\title{
Pechstein - zwischen Palau und Pommern
}

\section{Einer der bedeutendsten Vertreter des deutschen Expressionismus, Mitgliedschaft in der Künstlergruppe „Die Brücke", Mitbegründer der „Neuen Sezession" - das alles war Max Pechstein. Auf dem Titelbild dieser Ausgabe hat er seinen zweiten Sohn Frank verewigt.}

$\mathrm{H}$ ermann Max Pechstein wurde am 31. Dezember 1881 in Zwickau geboren, ging dort zur Schule und begann mit 17 Jahren eine Lehre als Dekorationsmaler. Ab 1900 besuchte er die staatliche Kunstschule und wurde zwei Jahre später Meisterschüler an der Dresdner Kunstakademie mit höchster Auszeichnung. Erich Heckel (1883-1970) und Ernst Ludwig Kirchner (1880-1938) bewegten ihn 1906 zum Eintritt in die expressionistische Künstlervereinigung „Die Brücke“, die als eingeschworene Gemeinschaft von 1905 bis 1913 bestand. 1908 zog er nach Berlin und trat der „Berliner Sezession“ bei. Nachdem dort Gemälde der Brücke-Maler abgelehnt wurden, gründete er 1910 die Gruppe „Neue Sezession“.

Von 1909 bis 1912 hielt Pechstein sich an den Moritzburger Seen und im Fischerdorf Nidden auf der Kurischen Nehrung im damaligen Ostpreußen auf. Die sich dort seit 1909 entwickelnde Künstlerkolonie „Sandakademie“, auch „Barbizon der Nehrung“ genannt, hat er bis 1939 maßgeblich beeinflusst. Dabei stilisierte er die Einheit von Kunst und Leben - seine Idealvorstellung eines Künstlers. Seine kurzen, nebeneinander gesetzten Pinselstriche erinnern an van Gogh. Seine Gemälde sind von Farbigkeit geprägt („kurische Farben“).

\section{Südseeparadies}

Seit dem 18. Jahrhundert besuchten Europäer - angelockt von paradiesischen Vorstellungen - die Südsee, deren Kulturzeugnisse sie in den Völkerkundemuseen bewundern konnten. Völkerausstellungen tourten durch ganz Deutsch- land. Pechstein hatte zudem bei seinem Paris-Aufenthalt die Südsee-Bilder von Paul Gaugin (1848-1903) kennengelernt. Und so fuhr er mit seiner ersten Frau Lotte (Charlotte Kaprolat), die er 1911 geheiratet hatte, 1914 über Hongkong in der Südsee auf die zu den deutschen Kolonien gehörenden Palau-Inseln östlich der Philippinen. Dort wollte er die Kunst der für primitiv gehaltenen Naturvölker studieren. Von 1909 bis 1920 malte er Lotte überwiegend als eher fülliges Südsee-typisches Modell. 1912 wurde der erste Sohn Paul Frank geboren; am gleichen Tag fertigte Pechstein eine Tuschezeichnung als Geburtsanzeige an. Aber einen Tag später starb das Neugeborene. Ein Jahr später wurde dann sein zweiter Sohn Max Frank geboren.

Max Pechstein hat Frank 1916 als Dreijährigen mit farbigen Bauklötzchen auf dem Boden sitzend gemalt („Junge mit Spielzeug“), dann 1917 („Der Sohn des Künstlers auf dem Sofa“) im Stile seiner Südseebilder. Auf dem betont flächenhaft farbigen Gemälde stützt sich Frank auf einer Liege lässig hingestreckt auf seinen Arm. Er trägt einen Südsee-grünen Anzug und zeigt einen dort üblichen Pagenähnlichen Haarschnitt, die Augen sind asiatisch schmal gezeichnet. In der Hand hält er die Drachenschnur seines vor ihm liegenden Schmetterlings. Die Rückwand hinter der Liege ziert eine Palau-Wandmalerei mit einer Einheimischen, die einem klein gezeichneten Tier eine Wasserschale reicht. Ein Jahr später fertigte Pechstein noch ein Bild seines Sohnes an („Liegender Knabe“, 1918) wieder auf einem Sofa mit einem Südsee typischen Bezug, davor ein Calla-Blumenstrauß.
1915 war Pechstein nach dem überraschenden Kriegsausbruch aus japanischer Gefangenschaft von den Palau-Inseln auf Umwegen über New York und Amsterdam mit seiner Frau nach Deutschland zurückgekehrt. Vor allem 1917 hatte er viele Palau-Gemälde (u. a. Palau-Landschaften, „Palau-Triptychon“ und graphische Zyklen) von seinem $\mathrm{Pa}$ radies, dem Aufenthalt von 1914 bis 1915, aufgearbeitet.

1921 entdeckte Pechstein Pommern. Viele seiner Bilder zeigen die Menschen und die Natur dieser Gegend. In Pommern erlebte er auch 1945 die Besetzung durch die Rote Armee, konnte aber noch nach Berlin ausreisen.

\section{Zuerst diffamiert, später geehrt}

1923 trennte sich Pechstein kurz vor seinem 40. Geburtstag von seiner ersten Frau und heiratete Marta Möller. Zwei Jahre später wurde sein dritter Sohn Mäki (Konrad Max) geboren. Staatspreise und Ehrendiplome folgten. Dann aber erklärten ihn die Nationalsozialisten nach 1933 zum entarteten Künstler, entfernten 326 seiner Werke aus den Museen und schlossen ihn aus der Akademie der Künste aus. Er erhielt Mal- und Ausstellungsverbot, konnte aber in den USA einen Teil seiner Werke ausstellen, die dadurch gerettet wurden. Wie auch andere Brücke-Maler, wurden seine Bilder in der Ausstellung „Entartete Kunst“ gezeigt. Während des Zweiten Weltkriegs wurden zahlreiche Werke vernichtet.

Zum Ende des Krieges verfasste er seine Erinnerungen, die aber erst 1960 erschienen. Nach der Verleihung der Ehrenbürgerschaft in Zwickau wurde er als Professor zu seinem 70. Geburtstag zum Ehrensenator der Hochschule für Bildende Künste Berlin ernannt. Am 29. Juni 1955 starb Pechstein in Berlin.

Dr. Joachim Gunkel 